\title{
Gecko-inspired nanocomposite coating based on setae-spatulae structure and dynamic adsorption-desorption mechanism
}

\author{
Ding Zeng', Tingfeng Zhao², Chengyang $\mathrm{Li}^{3}$, Baohong $\mathrm{Hao}^{4}$, Monan $\mathrm{Shi}^{5}$ \\ ${ }^{1}$ Research Institute of Highway Ministry of Transport, Beijing, China \\ 2,3,4,5 Department of Mechanical Engineering, Beijing Institute of Petrochemical Technology, \\ Beijing, 102617, China \\ ${ }^{4}$ Corresponding author

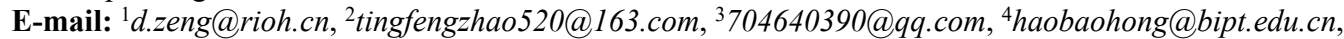 \\ 51641179265@qq.com
}

Received 4 February 2021; received in revised form 23 February 2021; accepted 4 March 2021 DOI https://doi.org/10.21595/vp.2021.21910

Check for updates

Copyright $(2021$ Ding Zeng, et al. This is an open access article distributed under the Creative Commons Attribution License, which permits unrestricted use, distribution, and reproduction in any medium, provided the original work is properly cited.

\begin{abstract}
A kind of multifunctional nanocomposite coating based on setae-spatulae structure of gecko is innovatively proposed, which was prepared by blending method. Potential polarization curve, electrochemical impedance spectroscopy (EIS) and salt spray test were analyzed respectively to analyze the corrosion inhibition effects. Results indicated that the impedance at low frequency region of epoxy resin (EP)/ZnO/ $/ \mathrm{Fe}_{2} \mathrm{O}_{3}$ ( $\gamma$-type) nanocomposite coating was the highest, which is 5.17 times of that of epoxy resin. Nanocomposite coating with multi-scale and multi-component nanoparticles has better pulverization resistance than blank epoxy resin and one-component coatings. The degree of protection of $\mathrm{EP} / \mathrm{ZnO} / \mathrm{Fe}_{2} \mathrm{O}_{3}(\gamma$-type) was highest.
\end{abstract}

Keywords: multifunctional gecko-inspired coating, multi-component nanoparticles, electrochemical impedance spectroscopy, salt spray test.

\section{Introduction}

More than $70 \%$ of our planet's surface is covered by interconnected oceans, which harbor a tremendous diversity of natural resources such as oil, gas, various minerals, etc. [1,2]. Steel materials are widely applied in the process of drilling and mining marine resources contributed to the excellent performances on corrosion resistance, strength and welding [3]. In particular, there is a rapidly increasing application in port machinery, offshore platform steel frame and steel trestle. Immersed steel equipment in seawater, however, suffered dreadful corrosion such as microbiologically induced corrosion and seawater corrosion. It caused huge economic losses associated with personal safety accident and natural catastrophes. Applying an anticorrosive coating on the metal surface can effectively reduce this phenomenon, but taken the service life of coating into account, the service life of ordinary coating is only 5-8 years, which is far from meeting the requirements of high durability in marine environment [4]. Therefore, developing a multifunctional coating with long service life and strong adhesive force that can apply in various environments and surfaces is necessary.

Learning from nature is the source of inspiration for human scientific creation. Mankind have benefited from close observation and utilization of nature especially from the time of Leonardo da Vinci [5], e. g. shark skin-inspired low-drag dirigibles and boat hulls, coatings based on the hydrophobic surface of a lotus leaf, adhesive tape and wall-climbing robots inspired by geckos. The gecko can adhere to the vertical walls and ceilings by using the hierarchical structure in the foot pad even in weightlessness. Its strong adhesion force is fascinating. Gecko-inspired materials design has gained considerable successful application in the area of aircraft, robots and adhesives [6], however, little in the field of metal corrosion. There are great potential to implement novel multi-functional bionic design of anti-corrosion materials to meet longer durability requirements of coatings. Multifunctional bioinspired nanocomposite coating based on setae-spatulae is 
innovatively proposed. Novel design in the scale and hierarchy of nanomaterial is implemented, which is expected to break through the performance limit of composite coating.

A kind of gecko-inspired nanocomposite coating based on setae-spatulae structure is innovatively proposed in this paper. First, the accelerated simulation corrosion experiment is used to simulate the corrosion process of the metal coating in the deep sea environment. Then, potential scanning, electrochemical impedance analysis, water resistance experiment and salt spray resistance experiment were carried out to verify the longer durability, higher adhesion and self-cleaning performance of the gecko-inspired nanocomposite coating. Finally, main conclusions were listed.

\section{Research method}

\subsection{Contact theory analysis}

The design of gecko-inspired nanocomposite coatings not only need to have a certain understanding of biological principles, but also need to study the mechanics of micro scale adhesive contact theory. There are two celebrated models that dominate the field of contact mechanics, the Johnson-Kendall-Roberts (JKR) model for elastic solids and the Derjaguin-Muller-Toporov (DMT) model for hard solids, respectively. In general, the JKR model is for biological systems [7]. It is assumed that the spatula of gecko have semi-spherical extremities, and its radius is set to $R$.

Combined Hertzian elasticity theory with Linear elastic fracture mechanics, regardless of the rate effect, the attractive force $P$ between the two bodies of radius $R$ for producing a contact area with radius $a$ can be calculated as follow [8]:

$P=\frac{4 \pi a^{3} E^{*}}{3 R}-\sqrt{8 \pi a^{3} \gamma^{*} E^{*}}$,

where $E^{*}$ is the Young's modulus of the contact pair, which can be obtained by:

$\left(E^{*}\right)^{-1}=\left(1-v_{1}^{2}\right)\left(E_{1}\right)^{-1}+\left(1-v_{2}^{2}\right)\left(E_{2}\right)^{-1}$,

where $E_{1}$ is elastic modulus of contact surface $1, E_{2}$ is elastic modulus of contact surface $2, v_{1}$ is Poisson's ratio of contact surface $1, v_{2}$ is Poisson's ratio of contact surface 2.

The pull-off force $P_{c}$ is obtained by taking $\frac{\partial P}{\partial a}=0$ [9]:

$P_{c}=-\frac{3}{2} \pi R \gamma^{*}$

where $\gamma^{*}$ Adhesion work.

The minus sign in Eq. (3) is used to denote tensile forces. When the contact area reaches to $R$, the adhesion stress can also be calculated by the Eq. (3).

When apparent contact area is fixed, the adhesion stress will increase by $n^{1 / 2}$ times if it is subdivided into $n$ smaller contacts [5]. It explains the reason why the hierarchical structure of gecko foot produces such a strong adhesion force.

\subsection{Research contents}

The contact theory analysis of gecko illustrated that the pull-out force/adhesion force at the contact point is independent of Young's modulus of semi-spherical extremities structure, the hierarchical structure is more critical. This is because the surface of the contact pair is uneven in microscopic conditions. The contact theory analysis provides inspiration for the selection and 
preparation of anti-corrosion coating materials.

Multicomponent biomimetic nanocomposite coating based on setae-spatulae structure of gecko was innovatively proposed. The realization of the dynamic adsorption desorption function of gecko-inspired nanocomposite coating depends on the size and type of the selected nanoparticles. In order to imitate "setae" and "spatulae" of the gecko toe pad, magnetic chiral nanoparticles were introduced, doped with other multi-component, multi-dimensional and multi-scale nanoparticles. Utilizing the unique two functions of chiral molecules (e.g., reversible double bonds, multiple grippers) and the synergy of multi-component nanoparticles, the design of setae-spatulae structure can be completed to achieve the ideal effect.

\subsection{Construction of gecko like foot structure model}

It is proposed to introduce multi-component nano additives of $\mathrm{Al}_{2} \mathrm{O}_{3}, \mathrm{ZnO}$ and $\mathrm{Fe}_{2} \mathrm{O}_{3}$, follow the principle of the lowest energy spontaneously, and coordinate uniformly according to the priority of bond energy under the joint action of van der Waals force and surface energy. "Interstitial" and "intercalation" self-assembly and "homogeneous dispersion" can be realized. With the help of multi-scale and multi-dimensional nano particles, the "gecko like keyhole structure" was imitated, The multi-scale $\mathrm{TiO}_{2}$ modification was used as the connector between large particles and chiral molecules, the chain structure on the keyhole structure was imitated by the spiral rod like ZnOnano particles, and the "sucker" small hand on the keyhole structure was imitated by the multi-dimensional high wear-resistant $\mathrm{Al}_{2} \mathrm{O}_{3}$. Finally, the design of dynamic adsorption-desorption effect of gecko foot was finished.

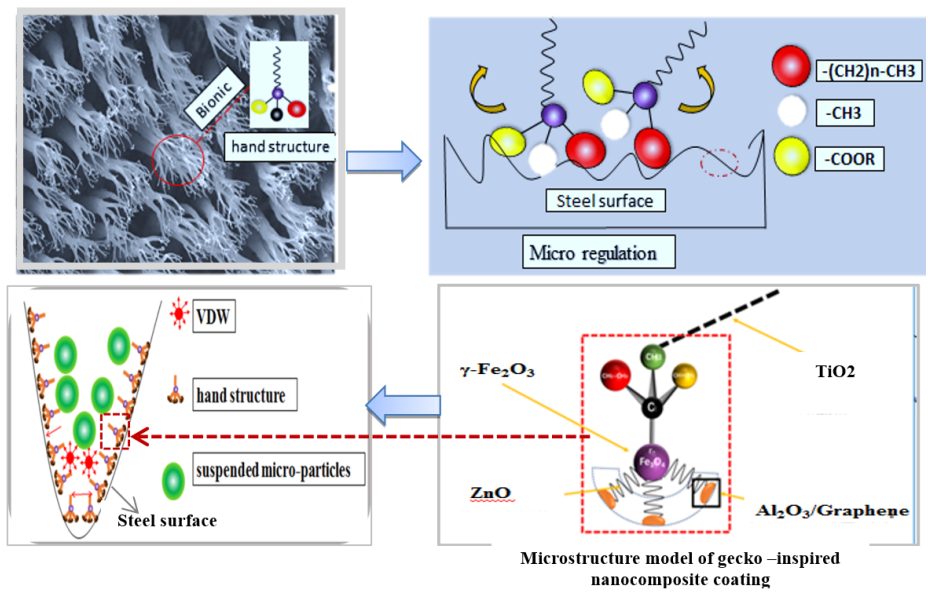

Fig. 1. Design of multi-component nano particle Compatibility Model of gecko-inspired nanocomposite coating

\subsection{Experimental details}

Firstly, blending method was used to prepare gecko-inspired nanocomposite coatings with one component, two-component and multi-component, respectively. Using blank epoxy resin (EP) coating and other multi-component coatings as a control group, the corrosion behavior of nanoparticles (e.g. $\mathrm{Fe}_{2} \mathrm{O}_{3}, \mathrm{Fe}_{3} \mathrm{O}_{4}, \mathrm{Al}_{2} \mathrm{O}_{3}, \mathrm{TiO}_{2}$ ) with different scales and components in $\mathrm{EP}$ coating was investigated. Secondly, the potential polarization curve of multi-component nanocomposite coating immersed in $5 \mathrm{wt} \% \mathrm{NaCl}$ environment, e.g. $\mathrm{EP} / \mathrm{Fe}_{2} \mathrm{O}_{3}$ ( $\gamma$-type), $\mathrm{EP} / \mathrm{Fe}_{3} \mathrm{O}_{4}, \mathrm{EP} / \mathrm{Al}_{2} \mathrm{O}_{3}$, $\mathrm{EP} / \mathrm{TiO}_{2}, \mathrm{EP} / \mathrm{ZnO} / \mathrm{Fe}_{2} \mathrm{O}_{3}$ ( $\gamma$-type), was tested by electrochemical workstation respectively. Blocking and protective properties of all nanocomposite coatings were analyzed using electrochemical impedance spectroscopy (EIS). Finally, the accelerated corrosion effect of salt spray test was investigated. 


\section{Results and discussion}

\subsection{Electrochemical performance analysis}

Fig. 2 depicts the corrosion rate of steel plate and EP composite coating samples at different times. As the immersion time elapsed, the corrosion growth rate of $\mathrm{EP} / \mathrm{Fe}_{3} \mathrm{O}_{4}$ gecko-inspired nanocomposite coating was fastest, the highest $C_{r r}$ value is up to $0.00464 \mathrm{~mm} / \mathrm{a}$ after 168 hours immersion. This is due to $\mathrm{Cl}^{-}$reacts with pigments and plasticizers in the coating, the micropore of the coating is enlarged and the penetration speed of $\mathrm{Cl}^{-}$is accelerated. The corrosion growth trend of $\mathrm{EP} / \mathrm{Al}_{2} \mathrm{O}_{3}, \mathrm{EP} / \mathrm{TiO}_{2}, \mathrm{EP} / \mathrm{ZnO} / \mathrm{Fe}_{2} \mathrm{O}_{3}(\gamma$ type $)$ coatings is relatively stable, among which the average corrosion rate of $\mathrm{EP} / \mathrm{ZnO} / \mathrm{Fe}_{2} \mathrm{O}_{3}\left(\gamma\right.$ type) coating is the lowest, and the lowest $C_{r r}$ value is $0.0005 \mathrm{~mm} / \mathrm{A}$. Compared to $\mathrm{EP} / \mathrm{Fe}_{3} \mathrm{O}_{4}$ coating, its corrosion rate is reduced by an order of magnitude. The reason lies in that the coating with multi-component and multi-scale nano particles follows the principle of minimum free energy, which spontaneously realizes "interstitial" and "intercalation" self-assembly and compacts the structure. The corrosion rate of the coating decreases with the doping of multi-component and multi-scale nano additives, which proves that the addition of nano particles increases the contact area with metal substrate, and has the best anti-corrosion protection effect on steel members.

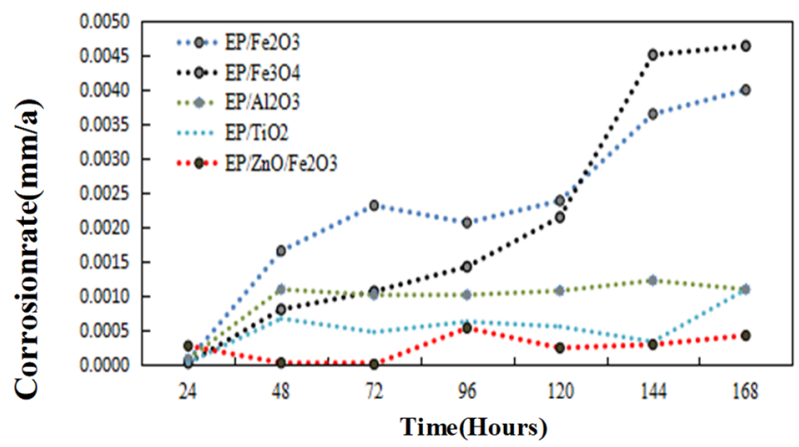

Fig. 2. Corrosion rate of steel plate and EP composite coating samples at different times

\subsection{Results of EIS}

The IMF in Bode diagram is often used to evaluate the anti-corrosion performance of coatings. The impedance modulus at $0.01 \mathrm{~Hz}|\mathrm{Z}|_{0.01 \mathrm{~Hz}}$ can directly reflect the corrosion protection properties of the coating on the internal migration of electrolyte [10]. The $|\mathrm{Z}|_{0.01 \mathrm{~Hz}}$ values of $\mathrm{EP}, \mathrm{EP} / \mathrm{Fe}_{2} \mathrm{O}_{3}$ $\left(\gamma\right.$-type), $\mathrm{EP} / \mathrm{Fe}_{3} \mathrm{O}_{4}, \mathrm{EP} / \mathrm{TiO}_{2}, \mathrm{EP} / \mathrm{Al}_{2} \mathrm{O}_{3}, \mathrm{EP} / \mathrm{ZnO} / \mathrm{Fe}_{2} \mathrm{O}_{3}(\gamma$-type) in the impedance modulus-frequency Bode diagram (Fig. 3(b)) are $1.13 \times 10^{5} \Omega \mathrm{cm}^{2}, 1.17 \times 10^{5} \Omega \mathrm{cm}^{2}, 2.09 \times 10^{5} \Omega \mathrm{cm}^{2}$, $3.02 \times 10^{5} \Omega \mathrm{cm}^{2}, 4.24 \times 10^{5} \Omega \mathrm{cm}^{2}$ and $5.84 \times 10^{5} \Omega \mathrm{cm}^{2}$ respectively. The IMF of each coating is above $1 \times 10^{5} \Omega \mathrm{cm}^{2}$. The IMF of EP is the lowest, the IMF of $\mathrm{EP} / \mathrm{ZnO} / \mathrm{Fe}_{2} \mathrm{O}_{3}$ ( $\gamma$-type) nanocomposite coating is the highest, which is 5.17 times of that of EP, showing better electrolyte barrier effect. This is attributed to the incorporation of multi-scale and multi-component nanoparticles resulting in the increase of contact area with steel plate, and the electrolyte diffusion length also increase.

The Bode phase angle-frequency curve in Fig. 3(c) also shows that the phase angle growth rate of $\mathrm{EP} / \mathrm{ZnO} / \mathrm{Fe}_{2} \mathrm{O}_{3}(\gamma$-type) composite coating increases faster than other coatings. It indicates that the time taken for $\mathrm{EP} / \mathrm{ZnO} / \mathrm{Fe}_{2} \mathrm{O}_{3}$ ( $\gamma$-type) composite coating to form a stable and dense passivation coating is shorter. Besides, it has a higher degree of adhesion to the steel plate surface. In conclusion, all of these results indicate higher degree of protection of $\mathrm{EP} / \mathrm{ZnO} / \mathrm{Fe}_{2} \mathrm{O}_{3}$ ( $\gamma$-type) than other composite coatings. 


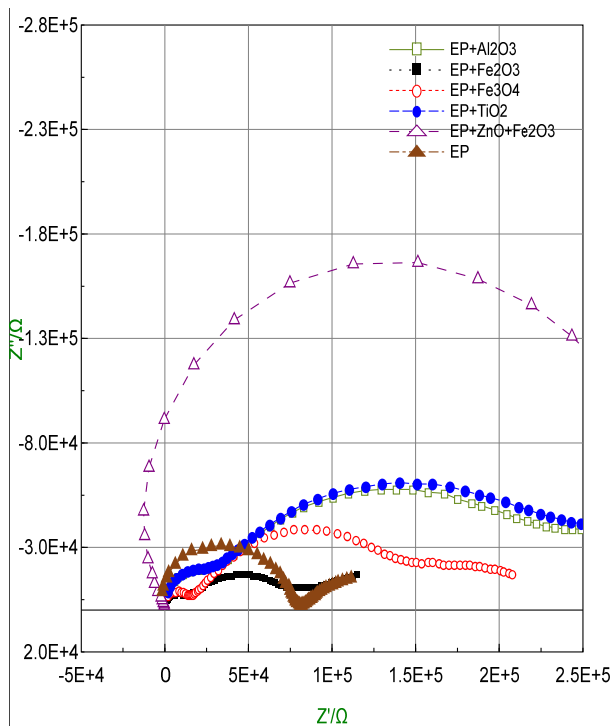

a) Model diagram

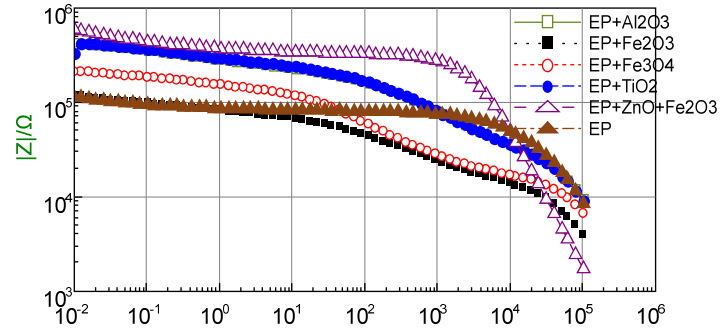

b) Impedance modulus diagram

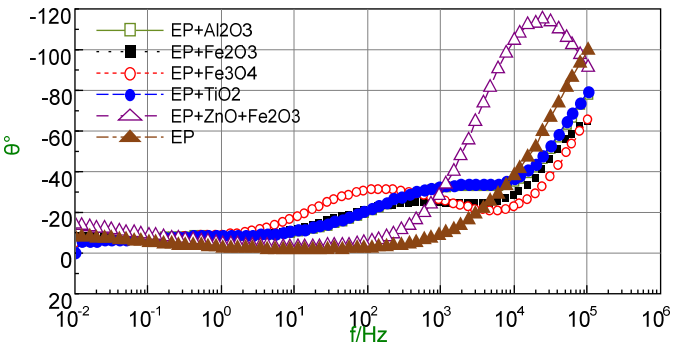

c) Phase angel Nyquist e-frequency curve of Bode diagram -frequency curve of Bode

Fig. 3. EIS diagram of gecko nanocomposite coating immersed in $5 \mathrm{wt} \% \mathrm{NaCl}$ solution after $168 \mathrm{~h}$ immersion

\subsection{Salt spray test}

The accelerated corrosion effect of salt spray test for about 150 days is as follows.

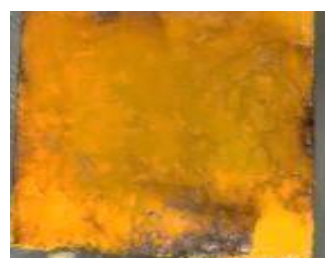

a) Blank EP

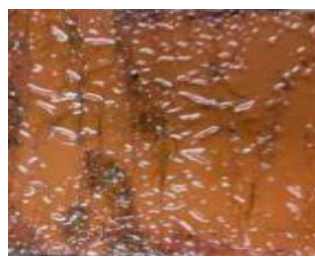

b) $\mathrm{EP} / \mathrm{Fe}_{2} \mathrm{O}_{3}(\gamma$-type $)$

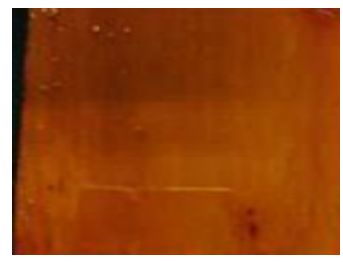

c) $\mathrm{EP} / \mathrm{ZnO} / \mathrm{Fe}_{2} \mathrm{O}_{3}$

Fig. 4. Pictures of salt spray test

It can be seen from Fig. 4 that after a long time of salt spray test, the surface of samples change obviously, accompanied by wrinkles, cracks, pitting and pits. With the increase of corrosion time, the number and depth of corrosion pits increase. The results show that blank EP is most severely corroded by salt spray, with obvious rust and peeling. However, the multi-component nanocomposite coating still maintains good gloss and uniformity, and only a few rust spots appeared, showing good corrosion resistance.

\section{Conclusions}

Multicomponent biomimetic nanocomposite coating based on the setae-spatulae structure of gecko was innovatively proposed, the effect of gecko-inspired nanocomposite coating with multi-component, multi-dimensional and multi-scale nanoparticles on the corrosion protection properties was studied on steel substrates. The impedance at low frequency region of EP was the lowest, the impedance at low frequency region of $\mathrm{EP} / \mathrm{ZnO} / \mathrm{Fe}_{2} \mathrm{O}_{3}(\gamma$-type) nanocomposite coating was the highest, which is 5.17 times of that of EP. EP/ZnO/ $/ \mathrm{Fe}_{2} \mathrm{O}_{3}(\gamma$-type) nanocomposite coating shows better electrolyte barrier effect. salt spray test showed better dispersion of $\mathrm{EP} / \mathrm{ZnO} / \mathrm{Fe}_{2} \mathrm{O}_{3}$ 
( $\gamma$-type) nanocomposite coating than $\mathrm{EP}, \mathrm{EP} / \mathrm{Fe}_{2} \mathrm{O}_{3}\left(\gamma\right.$-type), $\mathrm{EP} / \mathrm{Fe}_{3} \mathrm{O}_{4}, \mathrm{EP} / \mathrm{Al}_{2} \mathrm{O}_{3}$ and $\mathrm{EP} / \mathrm{TiO}_{2}$ coatings. Compared to epoxy resin, nanocomposite coating with multi-scale and multi-component nanoparticles has better pulverization resistance. All of these results indicate higher degree of protection of $\mathrm{EP} / \mathrm{ZnO} / \mathrm{Fe}_{2} \mathrm{O}_{3}(\gamma$-type) than other composite coatings.

\section{Acknowledgements}

1) Special fund project for Basic Scientific Research Business Expenses of Central Public Welfare Research Institutes, Item no. 2018-9024, project name: Structural Design and Key Technology of Nano-Composite Coating for Bridge Steel Substrates.

2) The Interdisciplinary Training Program of High Level Talents in Beijing Higher Education Institutions in 2019, project name: Amplification Test and Achievement Promotion of "Three-Imitation" Nano-Composite Coating for Bionic Self-Repairing/Imitation Lotus Leaf/Imitation Gecko Toes, Item No. 2019100170419.

3) Talent Training Program of Beijing Time Education Commission Item No. 2020J00044, project name: Study on Biomimetic Self-Healing Functional Group Construction and Dynamic Adsorption-Desorption Adhesion Mechanism of Nanocomposite Coatings.

\section{References}

[1] Claudet J., et al. A roadmap for using the UN decade of ocean science for sustainable development in support of science, policy, and action. One Earth, Vol. 2, Issues 1, 2020, p. 34-42.

[2] Ibarbalz F. M., et al. Global trends in marine plankton diversity across kingdoms of life. Cell, Vol. 179, 2019, p. 1084-1097.

[3] Zhang Qiaoxia, Xu Mo, Wang Xiutong, Li Hong, Wei Qinyi Research progress of heavy-duty anticorrosive coating applied on marine steel structure. Equipment Environmental Engineering, Vol. 12, 2015, p. 60-65.

[4] Zhang Yan, Huang Yajuan, et al. Analysis on the development of deep sea anticorrosive coatings. Modern Salt and Chemical Industry, Vol. 45, 2018, p. 18-19.

[5] Arzt Eduard Biological and artificial attachment devices: Lessons for materials scientists from flies and geckos. Materials Science and Engineering C, Vol. 26, Issue 8, 2006, p. 1245-1250.

[6] Takahashi K., et al. Flexibility and Poisson effect on detachment of gecko-inspired adhesives. International Journal of Adhesion and Adhesives, Vol. 62, 2015, p. 55-62.

[7] Han Zhenhua, Shi Wankai, Xiao Yangyi, Li Liangjun Adhesive contact analysis between rough surface based on JKR model. Journal of Mechanical Engineering, Vol. 52, 2016, p. 116-122.

[8] Spolenak Ralph, Gorb Stanislav, Gao Huajian, Arzt Eduard Effects of contact shape on the scaling of biological attachments. Proceedings of the Royal Society A: Mathematical, Physical and Engineering Sciences, Vol. 461, 2005, p. 305-319.

[9] Padmamalini N., Ambujam K. Impedance and modulus spectroscopy of $\mathrm{ZrO}_{2}-\mathrm{TiO}_{2}-\mathrm{V}_{2} \mathrm{O}_{5}$ nanocomposite. Karbala International Journal of Modern Science, Vol. 2, Issue 4, 2016, p. 271-275.

[10] Gharagozlou M, Ramezanzadeh B, Baradaran Z. Synthesize and characterization of a novel anticorrosive cobalt ferrite nanoparticles dispersed in silica matrix (CoFe2O4-SiO2) to improve the corrosion protection performance of epoxy coating. Applied Surface Science, Vol. 377, 2016, p. $86-98$. 